Check for updates

Cite this: Mater. Adv., 2022, 3, 2131

Received 30th November 2021 Accepted 30th December 2021

DOI: 10.1039/d1ma01126j

rsc.li/materials-advances

\section{Molecular design of viologens to exhibit low-order liquid-crystalline phases $\dagger$}

\author{
Satoshi Arai, Yusuke Ohgi, Minami Takahashi, Khoa V. Le, (D) Takeo Sasaki and \\ Yumiko Naka (D)*
}

\begin{abstract}
Viologens that are useful as stimulus-responsive compounds and exhibit a low-order liquid-crystalline (LC) phase at relatively low temperatures (approximately $20^{\circ} \mathrm{C}$ ) can be developed into materials that combine redox properties with LC properties. We synthesised a viologen (12NNP12) having an asymmetric core, while maintaining its stimulus-responsive properties, with the aim of forming a loworder LC phase at ambient temperature. The synthesised 12 NNP12 exhibited low-order LC phases: smectic-A (SmA) and smectic-C (SmC). The SmC phase appeared over a wide temperature range (approximately $170{ }^{\circ} \mathrm{C}$ ) above $-4.2{ }^{\circ} \mathrm{C}$, and the layer shrinkage determined by $\mathrm{X}$-ray diffraction measurements was small, up to $1.3 \%$ over a temperature range of $115{ }^{\circ} \mathrm{C}$. Furthermore, we synthesised a viologen derivative (12NPN12) having a symmetric core and a compound (12NPP12) having an asymmetric core and a single ionic bonding site, and investigated the effect of the asymmetry of the core on the LC properties. When the rod core was asymmetrised by changing the position and number of ionic bonds, the development of low-order LC phases was observed. It was suggested that the intermolecular interactions were weakened by varying the position of the ionic bonding sites to asymmetrise the core. Even for viologens with an asymmetric core (nNNP12), an LC phase was not formed if the length $(n)$ of the alkyl chain was too short. However, it was found that the LC properties were affected more by the asymmetry of the rigid ionic part than that of the alkyl chain.
\end{abstract}

\section{Introduction}

A viologen is a well-known electrochromic compound and finds use in solar cells, organic batteries, and electrochromic devices because of its reversible redox reaction by the application of an electric field. ${ }^{1-5}$ The most stable state of a viologen is known to be a colourless dication, which can be reduced to a blue-violet radical cation by a one-electron reduction and to an orange quinoid state by a two-electron reduction. ${ }^{6}$ Interestingly, the one-electron reduction of the dication proceeds not only by the application of an electric field, but also by UV irradiation. Thus, a viologen is an appealing stimuli-responsive compound.

Moreover, viologens can be made to exhibit liquid-crystalline (LC) properties by designing their molecular structure. Although there is a lack of variety in the molecular structure, viologen derivatives have been reported to exhibit LC properties. For instance, general viologens with long alkyl chains attached to both ends of the $4,4^{\prime}$-bipyridine core exhibit high-order LC phases. ${ }^{7-9}$ In contrast, $\pi$-extended viologens with one aromatic ring attached

Department of Chemistry, Faculty of Science, Tokyo University of Science, 1-3 Kagurazaka, Shinjuku-ku, Tokyo 162-8601, Japan. E-mail: naka@rs.tus.ac.jp $\dagger$ Electronic supplementary information (ESI) available. See DOI: 10.1039/ d1ma01126j to each of the 4 and $4^{\prime}$ positions of the bipyridine core have been reported to exhibit a low-order LC phase (SmA). ${ }^{10-12}$ However, none of them exhibit a low-order LC phase at ambient temperature (approximately $20 \pm 15{ }^{\circ} \mathrm{C}$ with no need for temperature control), and there are numerous extended viologens that do not exhibit an isotropic phase because the LC-isotropic phase-transition temperature is higher than the decomposition temperature. In simple viologens consisting of a bipyridine core and alkyl chains, there is no report of the formation of the SmC phase in which the molecules are tilted from the layer normal. Generally, compounds that exhibit low-order LC phases such as nematic, SmA and SmC at ambient temperature are useful as LC materials. It is also important for LC materials to exhibit an isotropic phase, as the alignment of LC molecules can be efficiently controlled by lowering the temperature from isotropic. If the LC phase of the stimuliresponsive viologen can be made to be lower-order and lowertemperature, then viologen materials with the advantages of LC characteristics can be further developed, leading to an expansion of their applications such as holographic materials.

In ionic viologens as well as in non-ionic LC compounds, the appearance of the LC phase is strongly influenced by the length of the alkyl chain. For general viologens with a bipyridine core, the shorter the alkyl chains are, the narrower the temperature range of the LC phase tends to be. ${ }^{7,9}$ It has also been reported 


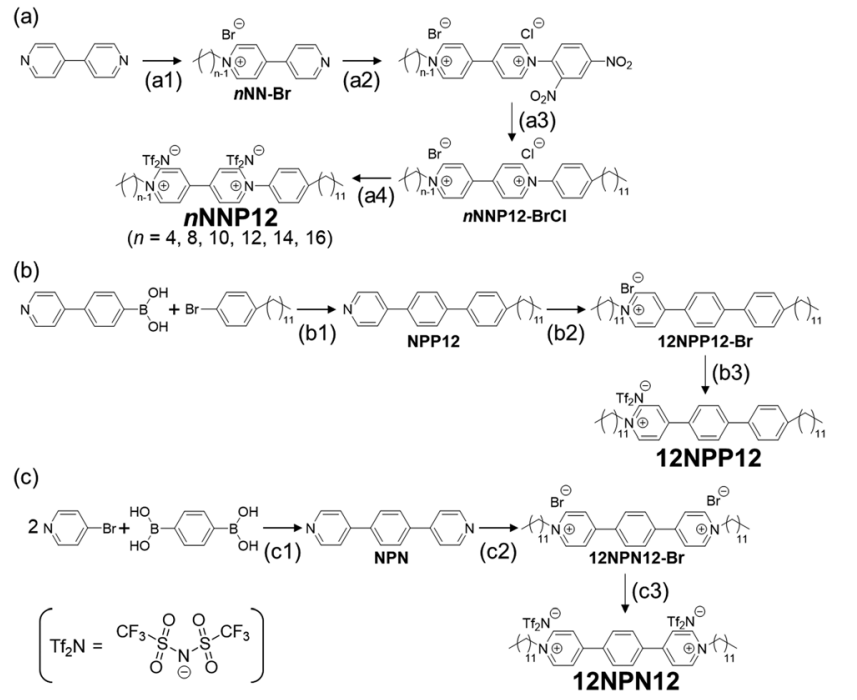

Scheme 1 Synthetic routes of extended viologen derivatives. (a) nNNP12 ( $n=4,8,10,12,14,16)$, (b) 12NPP12, and (c) 12NPN12. N, P, $n$, and 12 in 12NPN12, nNNP12 and 12NPP12 represent a pyridine ring, an aromatic ring, the number of carbons in the alkyl chain attached to the pyridine ring, and a dodecyl group, respectively. Unless otherwise stated, the counter anion is bis((trifluoromethyl)sulfonyl)imide $\left(\mathrm{Tf}_{2} \mathrm{~N}\right)$.

that the greater the difference in the length of the two alkyl chains attached to both ends of the bipyridine core, that is, the more asymmetric the viologen is depending on the length of the alkyl chains, the lower the crystal-LC phase transition temperature $\left(T_{\mathrm{Cry}-\mathrm{LC}}\right)$ tends to be. ${ }^{8}$ Therefore, to show a loworder LC phase at ambient temperature, the molecular structure of the viologens should be asymmetric, while maintaining the length of their alkyl chains. Moreover, the type of counter anion also contributes to the formation of the LC phase for the viologens. ${ }^{11-13}$ We speculated that the position of the cation $\left(\mathrm{N}^{+}\right)$in the rigid moiety would have a substantial influence on the formation of the LC phase because the counter anions are expected to be located near the $\mathrm{N}^{+}$of the rigid moiety. In this study, we designed and synthesised viologens with an asymmetrised extended core by varying the position of the cation and long alkyl chains to form a low-order LC phase at about $20{ }^{\circ} \mathrm{C}$. The effects of the asymmetric core on the LC properties were investigated using extended viologens with a three-ring core consisting of pyridine and aromatic rings.

\section{Experimental}

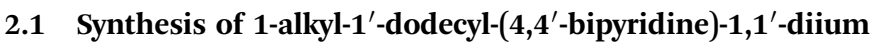
bis((trifluoromethyl)sulfonyl)imide $(n N N P 12)(n=4,8,10,12$, 14, 16)

$n$ NNP12 was synthesised in four steps, as shown in Scheme 1(a) and the sections (step a1-a4) below. First, an alkyl chain was introduced onto one side of the $4,4^{\prime}$-bipyridine by the Menshütkin reaction, ${ }^{14}$ and then an aromatic ring was introduced onto the other side by a two-step Zinke reaction. ${ }^{15-17}$ Finally, the halide ions were exchanged with bis((trifluoromethyl)sulfonyl)imide $\left(\mathrm{Tf}_{2} \mathrm{~N}\right)^{5,18}$
2.1.1 (Step a1) 1-alkyl-(4,4'-bipyridine)-1-ium bromide (nNN-Br) synthesis. 4,4'-Bipyridine (0.993 g, $6.36 \mathrm{mmol}$ ) and bromo alkane $(10.0 \mathrm{mmol}, n=4,8,10,12,14$, or 16) were dissolved in dry DMF $(10 \mathrm{~mL})$ and heated to $120{ }^{\circ} \mathrm{C}$ in a nitrogen atmosphere and stirred for $2 \mathrm{~h}$. The reaction mixture was left in an ice bath, and the precipitated solid was removed by filtration. The filtrate was concentrated by evaporation to obtain a solid. The obtained solid was dissolved in ethyl acetate, and the remaining solid was collected by filtration. A yellowish white solid was obtained. The yields of $4 \mathrm{NN}-\mathrm{Br}, 8 \mathrm{NN}-$ $\mathrm{Br}, 10 \mathrm{NN}-\mathrm{Br}, 12 \mathrm{NN}-\mathrm{Br}, 14 \mathrm{NN}-\mathrm{Br}$, and $16 \mathrm{NN}-\mathrm{Br}$ were $20.0 \%$, $58.2 \%, 57.2 \%, 54.3 \%, 57.3 \%$ and $78.0 \%$, respectively.

2.1.2 (Step a2) 1-(2,4-dinitrophenyl)-1' $-n$-alkyl-(4,4'-bipyridine)-1,1'-diium bromide chloride synthesis. A dinitrophenyl group, which is the leaving group in the Zinke reaction, was attached to the pyridine of $n \mathrm{NN}-\mathrm{Br}(n=4,8,10,12,14$, or 16). First, $n \mathrm{NN}-\mathrm{Br}(1.49 \mathrm{mmol}, n=4,8,10,12,14$, or 16) and 1-chrolo-2,4-dinitrobenzene $(0.668 \mathrm{~g}, 3.30 \mathrm{mmol})$ were added to a flask, and then the mixture was stirred at $80{ }^{\circ} \mathrm{C}$ for $3 \mathrm{~h}$ in a nitrogen atmosphere. As precipitation occurred, a small amount of acetone was added, and the mixture was stirred for another $1.5 \mathrm{~h}$. The reaction solution was concentrated using an evaporator. Warm chloroform was added to the obtained precipitate to wash away the raw material. A yellow solid was formed. The yields of the products $(n=4,8,10,12,14$, and 16) were $77.0 \%, 51.9 \%, 89.6 \%, 59.8 \%, 87.7 \%$ and $87.3 \%$, respectively.

2.1.3 (Step a3) 1-alkyl-1'-dodecyl-(4,4'-bipyridine)-1,1' -diium bromide chloride (nNNP12-BrCl) synthesis. A mixture of the compound obtained in step a2 $(0.888 \mathrm{mmol}), p$-dodecylaniline $(0.810 \mathrm{~g}, 3.10 \mathrm{mmol})$, water $(32 \mathrm{~mL})$ and ethanol $(48 \mathrm{~mL})$ was stirred at $90{ }^{\circ} \mathrm{C}$ for $48 \mathrm{~h}$. The raw material and the leaving group were removed by adding acetone to the solid obtained by concentrating the reaction solution and stirring. The yellow solid that undissolved was collected by gravity filtration. The yields of 4NNP12-BrCl, 8NNP12-BrCl, 10NNP12-BrCl, 12NNP12-BrCl, $14 \mathrm{NNP} 12-\mathrm{BrCl}$, and $16 \mathrm{NNP} 12-\mathrm{BrCl}$ were $93.7 \%, 80.3 \%, 40.1 \%$, $90.8 \%, 95.1 \%$ and $90.5 \%$, respectively.

2.1.4 (Step a4) 1-alkyl-1'-dodecyl-(4,4'-bipyridine)-1, $\mathbf{1}^{\prime}$-diium bis((trifluoromethyl)sulfonyl)imide (nNNP12) synthesis. A mixture of $n \mathrm{NNP} 12-\mathrm{BrCl}(0.635 \mathrm{mmol}, n=4,8,10,12,14$ or 16$)$, lithium bis(trifluoromethanesulfonyl)imide $\left(\operatorname{LiTf}_{2} \mathrm{~N} ; 0.532 \mathrm{~g}, 1.85 \mathrm{mmol}\right.$ ) and methanol was stirred at ambient temperature for $24 \mathrm{~h}$. The concentrated reaction solution was then added dropwise into pure water. The target product was precipitated and collected via suction filtration. To improve the reaction rate, the resulting product was reacted with $\operatorname{LiTf}_{2} \mathrm{~N}$ again and purified by reprecipitation. The obtained products were vacuum dried in a desiccator containing silica gel for over $24 \mathrm{~h}$. The yields of 4NNP12, 8NNP12, 10NNP12, 12NNP12, 14NNP12, and 16NNP12 were 45.4\%, 55.4\%, $65.0 \%, 77.8 \%, 58.0 \%$ and $87.4 \%$, respectively. Elemental analysis of the final product, $n \mathbf{N N P 1 2}(n=4,8,10,12,14,16)$ was performed. Anal. calcd for $\mathrm{C}_{36} \mathrm{H}_{46} \mathrm{~F}_{12} \mathrm{~N}_{4} \mathrm{O}_{8} \mathrm{~S}_{4}$ (4NNP12): C, 42.43; $\mathrm{H}, 4.55$; N, 5.50. Found: C, 42.47; H, 4.51; N, 5.41. Anal. calcd for $\mathrm{C}_{40} \mathrm{H}_{54} \mathrm{~F}_{12} \mathrm{~N}_{4} \mathrm{O}_{8} \mathrm{~S}_{4}$ (8NNP12): C, 44.69; H, 5.06; N, 5.01. Found: C, 44.92; $\mathrm{H}, 4.88 ; \mathrm{N}$, 4.96. Anal. calcd for $\mathrm{C}_{42} \mathrm{H}_{58} \mathrm{~F}_{12} \mathrm{~N}_{4} \mathrm{O}_{8} \mathrm{~S}_{4}$ 
(10NNP12): C, 45.73; H, 5.30; N, 5.08. Found: C, 46.01; H, 5.49; N, 5.38. Anal. calcd for $\mathrm{C}_{44} \mathrm{H}_{62} \mathrm{~F}_{12} \mathrm{~N}_{4} \mathrm{O}_{8} \mathrm{~S}_{4}$ (12NNP12): C, 46.72; $\mathrm{H}$, 5.52; N, 4.95. Found: C, 46.78; H, 5.34; N, 4.95. Anal. calcd for $\mathrm{C}_{46} \mathrm{H}_{66} \mathrm{~F}_{12} \mathrm{~N}_{4} \mathrm{O}_{8} \mathrm{~S}_{4}$ (14NNP12): C, 47.66; H, 5.74; N, 4.83. Found: C, 47.79; $\mathrm{H}, 5.73 ; \mathrm{N}$, 4.72. Anal. calcd for $\mathrm{C}_{48} \mathrm{H}_{70} \mathrm{~F}_{12} \mathrm{~N}_{4} \mathrm{O}_{8} \mathrm{~S}_{4}$ (16NNP12): C, 48.56; H, 5.94; N, 4.72. Found: C, 48.61; H, 6.01; $\mathrm{N}, 4.69$. The decomposition temperatures $\left(T_{\mathrm{d}}\right)$ of 4NNP12, 8NNP12, 10NNP12, 12NNP12, 14NNP12, and 16NNP12 in nitrogen were $333.3{ }^{\circ} \mathrm{C}, 318.0{ }^{\circ} \mathrm{C}, 323.3{ }^{\circ} \mathrm{C}, 328.9{ }^{\circ} \mathrm{C}, 326.2{ }^{\circ} \mathrm{C}$ and $343.8{ }^{\circ} \mathrm{C}$. The $T_{\mathrm{d}} \mathrm{S}$ were measured by thermogravimetric analysis (TGA, Bruker-AXS, TG-DTA2010SA) in nitrogen.

\subsection{Synthesis of 1-dodecyl-4-(4'-dodecyl-[1,1' -biphenyl]-4-yl) pyridine-1-ium bis(trifluoromethanesulfonyl)imide (12NPP12)}

12NPP12 was synthesised in three steps as shown in Scheme 1(b) and the sections (step b1-b3) below. First, a rigid moiety was synthesised by the Suzuki-Miyaura coupling reaction. Next, a dodecyl group was introduced into the pyridine form by the Menshütkin reaction. ${ }^{14}$ Finally, the counter anion was exchanged with $\mathrm{Tf}_{2} \mathrm{~N} .{ }^{5,18}$

2.2.1 (Step b1) 4-(4'-dodecyl-[1,1'-biphenyl]-4yl) pyridine (NPP12) synthesis. (4-(Pyridine-4-yl)phenyl) boronic acid $(0.400 \mathrm{~g}, 2.01 \mathrm{mmol}), \mathrm{K}_{2} \mathrm{CO}_{3}(0.833 \mathrm{~g}, 6.03 \mathrm{mmol})$, and tetrakis(triphenylphosphine) palladium $(0)\left(\mathrm{Pd}\left(\mathrm{PPh}_{3}\right)_{4}, 0.0233 \mathrm{~g}\right.$, $1.00 \mathrm{~mol} \%$ ) were added to a three-necked flask attached to a dropping funnel and a reflux condenser, and the flask was replaced with nitrogen gas. Nitrogen gas was bubbled in a mixture of 1-bromo-4-dodecylbenzene $(0.672 \mathrm{~mL}, 2.21 \mathrm{mmol})$, toluene $(100 \mathrm{~mL})$, water $(50 \mathrm{~mL})$, and ethanol $(50 \mathrm{~mL})$ in a dropping funnel. The solution was poured into a flask and stirred at $110{ }^{\circ} \mathrm{C}$ for $43 \mathrm{~h}$ under reflux. The reaction solution was filtered through Celite to remove the Pd catalyst and then purified using liquid-liquid extraction techniques. The solid precipitated after concentration was recrystallised with ethyl acetate to yield a grey solid. The yield of NPP12 was $76.5 \%$.

2.2.2 (Step b2) 1-dodecyl-4-(4'-dodecyl-[1,1'-biphenyl]-4-yl) pyridine-1-ium bromide (12NPP12-Br) synthesis. A mixture of NPP12 (0.464 g, $1.54 \mathrm{mmol})$, 1-bromodecane $(0.406 \mathrm{~mL}$, $1.69 \mathrm{mmol})$ and dry DMF $(20 \mathrm{~mL})$ was stirred at $110{ }^{\circ} \mathrm{C}$ for $41 \mathrm{~h}$ under reflux. After confirming the completion of the reaction by thin-layer chromatography (TLC), the reaction system was cooled in an ice bath. A yellow solid was obtained by filtration. The yield of $12 \mathrm{NPP} 12-\mathrm{Br}$ was $75.9 \%$.

2.2.3 (Step b3) 1-dodecyl-4-(4'-dodecyl-[1,1'-biphenyl]-4-yl) pyridine-1-ium bis(trifluoromethanesulfonyl)imide (12NPP12) synthesis. The counter anion of 12NPP12-Br was exchanged. 12NPP12-Br (0.464 g, $0.715 \mathrm{mmol})$ and $\operatorname{LiTf}_{2} \mathrm{~N}(0.238 \mathrm{~g}$, $0.829 \mathrm{mmol}$ ) were dissolved in methanol and stirred at $60{ }^{\circ} \mathrm{C}$ for $48 \mathrm{~h}$ under reflux. The reaction solution was concentrated by evaporation to obtain a yellow solid. The resulting solid was washed with pure water. The above procedure was repeated three times. The yield of 12NPP12 was 91.3\%. Anal. calcd for $\mathrm{C}_{45} \mathrm{H}_{66} \mathrm{~F}_{6} \mathrm{~N}_{2} \mathrm{O}_{4} \mathrm{~S}_{2}$ (12NPP12): C, 60.83; H, 7.36; N, 3.30. Found: C, $60.97 ; \mathrm{H}, 7.66 ; \mathrm{N}, 3.24$. The $T_{\mathrm{d}}$ of $12 \mathrm{NPP12}$ in nitrogen was $352.3{ }^{\circ} \mathrm{C}$.

\subsection{Synthesis of $4,4^{\prime}$-(1,4-phenylene) bis(1-dodecylpyridin-1-} ium) bis(trifluoromethanesulfonyl)imide (12NPN12)

The extended viologen (12NPN12) was synthesised by the Suzuki-Miyaura coupling reaction, followed by the Menshütkin reaction ${ }^{14}$ and ion exchange with $\mathrm{Tf}_{2} \mathrm{~N}^{5,18}$

2.3.1 (Step c1) 1,4-di(pyridine-4-yl) benzene (NPN) synthesis. 4-Bromopyridine (2.79 g, $1.44 \mathrm{mmol}$ ), 1,4-phenylenediboronic acid (1.00 g, $6.03 \mathrm{mmol}), \mathrm{K}_{2} \mathrm{CO}_{3}(2.74 \mathrm{~g}, 19.8 \mathrm{mmol}), \mathrm{Pd}\left(\mathrm{PPh}_{3}\right)_{4}$ (0.159 g, $0.998 \mathrm{~mol} \%)$, toluene $(150 \mathrm{~mL})$, ethanol $(75 \mathrm{~mL})$ and water $(75 \mathrm{~mL})$ were stirred in a nitrogen atmosphere at $120{ }^{\circ} \mathrm{C}$ for $96 \mathrm{~h}$ with reflux. After the reaction solution was cooled, the Pd catalyst was removed by filtration using Celite. The precipitated solid after concentration was dissolved in chloroform, and impurities were removed from the chloroform solution by washing with water using a separatory funnel. The dissolved solid was then extracted with aqueous hydrochloric acid solution $(\mathrm{pH}=2-3)$. The resulting aqueous phase was adjusted to $\mathrm{pH} 8-9$ with a saturated sodium hydroxide solution, and the precipitate was collected by suction filtration. A yellowish-white solid was obtained in an $81.1 \%$ yield.

2.3.2 (Step c2) 4,4'-(1,4-phenylene) bis(1-dodecylpyridin-1ium) dibromide (12NPN12-Br) synthesis. NPN (1.13 g, $4.67 \mathrm{mmol})$ and $n$-bromododecane $(12 \mathrm{~mL}, 10.0 \mathrm{mmol})$ dissolved in DMF (15 mL) were stirred in a nitrogen atmosphere at $120{ }^{\circ} \mathrm{C}$ for $48 \mathrm{~h}$ with reflux. The flask was placed in an ice bath to cool the system and allow precipitation. The yellowish-white precipitate was collected by suction filtration, and the resulting precipitate was dried under vacuum. The yield of 12NPN12-Br was $90.5 \%$.

2.3.3 (Step c3) 4,4'-(1,4-phenylene) bis(1-dodecylpyridin-1ium) bis(trifluoromethanesulfonyl)imide (12NPN12) synthesis. 12NPN12-Br (1.00 g, $1.37 \mathrm{mmol}), \operatorname{LiTf}_{2} \mathrm{~N}(1.92 \mathrm{~g}, 6.85 \mathrm{mmol})$ and methanol $(200 \mathrm{~mL})$ were stirred for $72 \mathrm{~h}$ at ambient temperature. The solid obtained by concentrating the solution was washed with pure water and then dried under vacuum. The yield of 12NPN12 was 95.6\%. Anal. Calcd for $\mathrm{C}_{44} \mathrm{H}_{62} \mathrm{~F}_{12} \mathrm{~N}_{4} \mathrm{O}_{8} \mathrm{~S}_{4}$ (12NPN12): C, 46.72; H, 5.52; N, 4.95. Found: C, 47.02; H, 4.83; $\mathrm{N}, 4.79$. The $T_{\mathrm{d}}$ of $12 \mathrm{NPN} 12$ in nitrogen was $346.3{ }^{\circ} \mathrm{C}$.

\subsection{Confirmation of synthesis}

The progress of the reaction was confirmed by the ${ }^{1} \mathrm{H}$-nuclear magnetic resonance $\left({ }^{1} \mathrm{H}-\mathrm{NMR}\right)$ measurements of $\mathrm{CDCl}_{3}$ or DMSO$\mathrm{d}_{6}$ solution (JEOL, JNM-ECS300, $300 \mathrm{MHz}$ ). The final product was also analysed by ${ }^{13} \mathrm{C}-\mathrm{NMR}$ measurement (JEOL, JNM-ECA500II, $500 \mathrm{MHz}$ ). ${ }^{1} \mathrm{H}$ - and ${ }^{13} \mathrm{C}-\mathrm{NMR}$ spectra obtained for all compounds are available in the ESI. $\dagger$ The counter-anion exchange was identified using time-of-flight mass spectrometry (ESI-TOF-MS; JEOL, JMS-T100LP AccuTOF) and Fourier transform infrared spectroscopy using the KBr pellet method (FT-IR; JASCO, FT/IR 4200). The purity of the compounds was evaluated by elemental analysis (PerkinElmer 2400 Series II CHNS/O Analyser).

\subsection{Investigation of thermotropic properties}

The thermotropic properties were determined by differential scanning calorimetry (DSC), TGA, polarised optical microscopy 
(POM), and X-ray refractive diffraction (XRD) measurements. In the DSC measurements, a DSC214 Polma (Netzsch) was used at a scanning speed of $5{ }^{\circ} \mathrm{C} \mathrm{min}^{-1}$. At least three cycles of measurement were performed to check the reproducibility. TGA was performed using a Bruker AXS TG-DTA2010SA instrument in nitrogen at a heating rate of $10{ }^{\circ} \mathrm{C} \mathrm{min}^{-1}$. Glass cells were fabricated using heat-resistant adhesives (Shin-Etsu Chemical Co., one-component RTV rubber deoxime type) for POM observation. The glass cell was filled with the viologen using capillary action at the isotropic-phase temperature of each viologen. The sample films were observed under crossed nicols using POM (Olympus, BX53LED) while controlling the temperature of the samples at a scanning rate of $5{ }^{\circ} \mathrm{C} \mathrm{min}^{-1}$ using a hot stage (Metter, FP82 FP80 HT). A Rigaku MiniFlex600 with a temperature controller was used for the XRD measurements. In the XRD measurements, the sample was heated from beneath, resulting in a temperature difference between the surface and the interior of the sample. In XRD results, the set temperature is indicated.

\section{Results and discussion}

\subsection{Synthesis of designed viologens}

To maintain the stimuli-responsive properties of viologens and to express the low-order LC phase at relatively low temperatures, we designed the viologens, $n$ NNP12s $(n=4,8,10,12,14$, 16), with long alkyl chains and a $\pi$-extended core whose symmetry was reduced by the position of the ionic bonding sites (Scheme 1(a)). The viologens were synthesised by the Menshütkin reaction, ${ }^{14}$ Zinke reaction ${ }^{15-17}$ and ion exchange reaction. ${ }^{5,18}$ Furthermore, to investigate the effect of ionic bonding sites (cations) in the core on the LC properties, viologen derivatives with different numbers and positions of $\mathrm{N}^{+}$, namely 12NPP12 and 12NPN12, respectively, were also synthesised (Schemes 1(b) and (c)). Bulky counter anions such as $\mathrm{Tf}_{2} \mathrm{~N}$ were chosen because LC properties have been reported in general viologens with $\mathrm{Tf}_{2} \mathrm{Ns} .{ }^{8}$ Here, $\mathrm{N}, \mathrm{P}, n$, and 12 in $n$ NNP12, 12NPP12, and 12NPN12 represent a pyridine ring, an aromatic ring, the number of carbon atoms in the alkyl chain attached to the pyridine ring, and a dodecyl group, respectively. The counter anions are not listed in the abbreviations but are all comprised of $\mathrm{Tf}_{2} \mathrm{~N}$. As shown in the Experimental section, we obtained $n$ NNP12, 12NPP12, and 12NPN12 with high purity.

\subsection{Effect of rigid sites on LC properties}

To investigate the effects of the asymmetric core on the LC properties, we compared the thermotropic properties of 12NNP12, 12NPP12, and 12NPN12 with alkyl chains of equal lengths. When 12 NNP12 was placed in a glass cell under a POM, the lowering of the temperature from $230{ }^{\circ} \mathrm{C}$ (isotropic phase temperature), at a rate of $5{ }^{\circ} \mathrm{C} \min ^{-1}$, caused the appearance of a fan-shaped texture at $221{ }^{\circ} \mathrm{C}$ and a brokenfan-shaped texture at $174{ }^{\circ} \mathrm{C}$ (Fig. 1(a)). The XRD measurements at each temperature revealed a broad peak around $2 \theta=20^{\circ}$ and
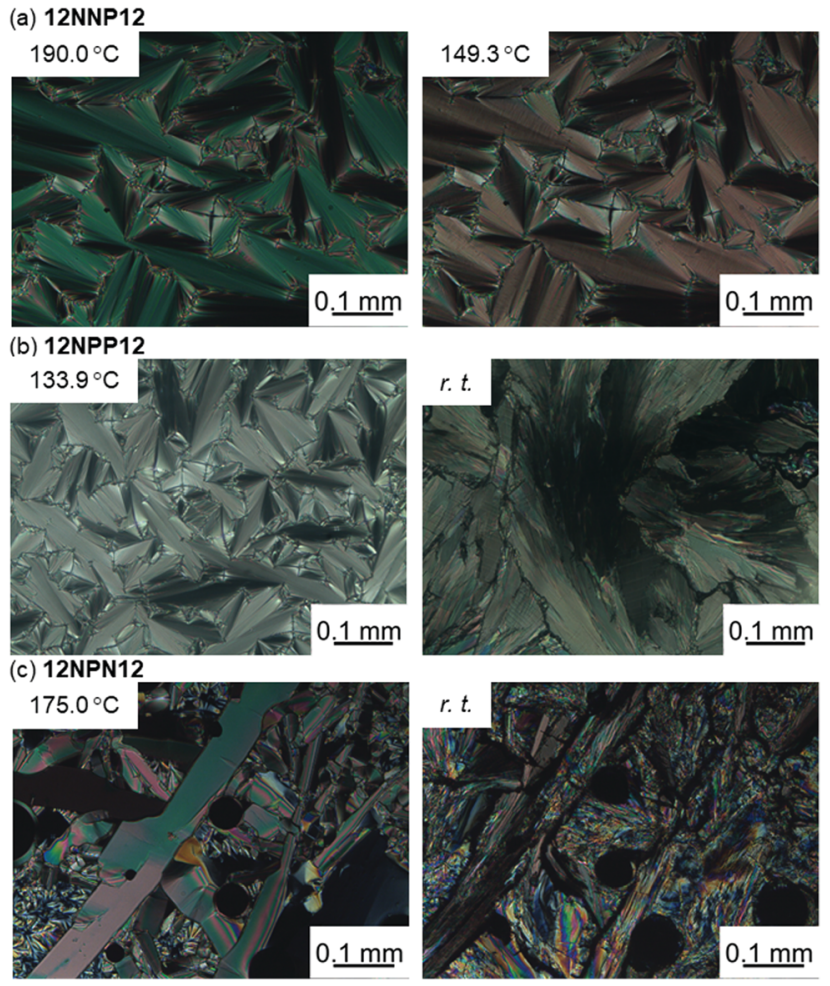

Fig. 1 POM textures of 12NNP12 (cell thickness $(d)=11.5 \mu \mathrm{m})$ (a), 12NPP12 $(d=11.9 \mu \mathrm{m})(\mathrm{b})$, and 12NPN12 $(d=11.0 \mu \mathrm{m})(\mathrm{c})$ as observed under crossed polarisers upon cooling from the isotropic phase at $5{ }^{\circ} \mathrm{C} \min ^{-1}$

sharp peaks in the low-angle region (Fig. 2(a)). The peaks marked with filled circles, as shown in Fig. 2, were derived from the layer of the smectic phase. The broad peaks indicate a lack of intermolecular regularity. The POM and XRD results of 12NNP12 showed two LC phases: smectic-A (SmA) and smectic-C (SmC), from the high-temperature side. Furthermore, we investigated the LC characteristics of both 12 NPP12 with a reduced number of $\mathrm{N}^{+}$and $12 \mathrm{NPN12}$ with different $\mathrm{N}^{+}$positions. As a
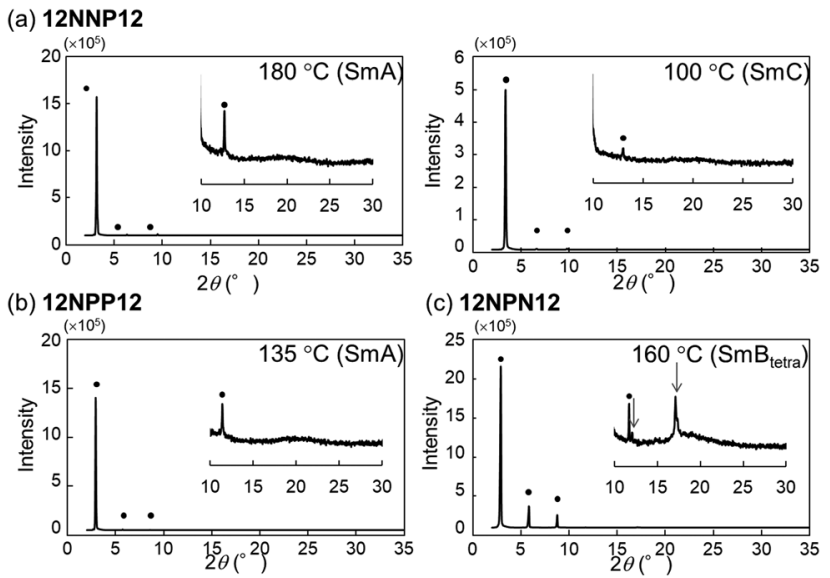

(c) 12NPN12

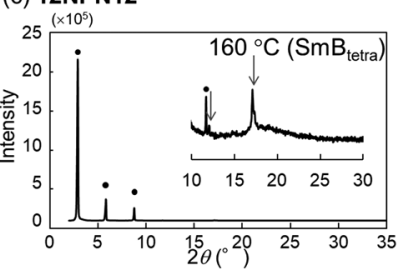

Fig. 2 X-Ray diffraction measurements of viologen derivatives synthesised in this study. (a) 12 NNP12 was set to $180{ }^{\circ} \mathrm{C}$ and $100{ }^{\circ} \mathrm{C}$, (b) 12 NPP12 was set to $135^{\circ} \mathrm{C}$ and (c) $12 \mathrm{NPN} 12$ was set to $160{ }^{\circ} \mathrm{C}$. 


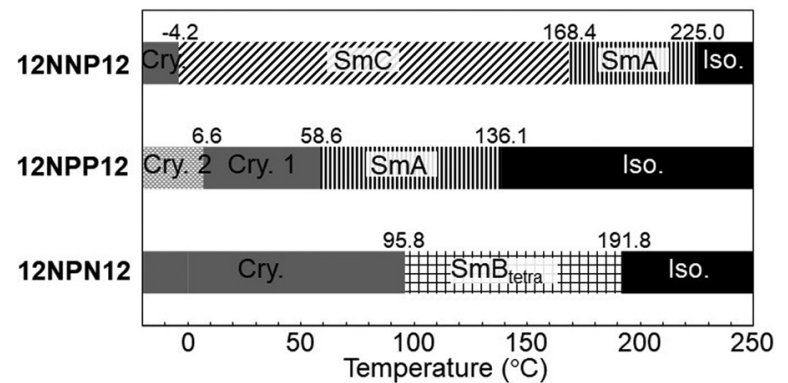

Fig. 3 Phase-transition temperatures of 12NNP12, 12NPP12 and 12NPN12 determined by DSC thermograms.

result, the LC phase was observed in both 12 NPP12 and 12NPN12, but appeared to be different. The SmA phase was observed, but an SmC phase was not observed in 12NPP12 which possesses only one ionic site (Fig. 1(b), 2(b) and 3). However, 12NPN12 with two ionic sites and a symmetric core showed a high-order LC phase. When the temperature of 12NPN12 was lowered at a rate of $5{ }^{\circ} \mathrm{C} \min ^{-1}$ from its isotropic phase, a texture was visible at $191.8{ }^{\circ} \mathrm{C}$ under a POM (Fig. 1(c)). Subsequently, a change in retardation was observed on further lowering the temperature to $95.8{ }^{\circ} \mathrm{C}$. The phase-transition enthalpy $(\Delta H)$ from the isotropic phase to the LC phase, calculated from the DSC thermograms, was as small as $12.0 \mathrm{~kJ} \mathrm{~mol}^{-1}$ (Table 1). XRD measurements showed the appearance of a broad peak at about $2 \theta=15-25^{\circ}$ and two sharp peaks at $2 \theta=11.7^{\circ}$ and $17.1^{\circ}$, in addition to the four sharp peaks in the low-angle region attributed to the layer marked by the filled circles (Fig. 2(c)). The $d$ values of the two sharp peaks at $2 \theta=11.7^{\circ}$ and $17.1^{\circ}$ were in the ratio of $1: 1 / \sqrt{ } 2$. Therefore, this high-order LC phase is most likely to be a smectic layer with tetragonal symmetry. ${ }^{19}$ As described above, 12NPN12 with a symmetric core exhibited a high-order LC phase, while 12NNP12 and 12NPP12 with an asymmetric core exhibited a low-order LC phase (SmA). To confirm whether the symmetry of the core affects the LC characteristics, we further synthesised a general viologen (12NN12) with a symmetric $4,4^{\prime}$-bipyridine core and the same alkyl chains and counter anions as present in 12NNP12, 12NPP12, and 12NPN12. Without exception, 12NN12 exhibited a high-order $\mathrm{SmB}_{\text {tetra }}$ phase, as shown in Fig. S1-S12 (ESI $\dagger$ ). It was suggested that compounds with a symmetric ionic core tend to form high-order smectic phases due to electrostatic interactions in the direction of the short axis of the molecule, while the intermolecular interactions were weakened by changing the position of the ionic bonding sites on the core to make them asymmetric, resulting in low-order LC phases.

Furthermore, we focused on the thermal stability of the crystalline and LC phases. The transition temperature from the LC phase to the crystalline phase $\left(T_{\text {LC-Cry }}\right)$ of the asymmetric compounds (12NNP12 and 12NPP12) was lower than that of the symmetric compounds (12NPN12) (Fig. 3). This shows that the thermal stability of the crystalline phase of the compounds with an asymmetric core was lower than that of the compounds with a symmetric core. Meanwhile, the isotropic-LC phasetransition temperature $\left(T_{\text {Iso-LC }}\right)$ of 12 NPP12 with one ionic bonding site was lower than that of 12NNP12 and 12NPN12 with two ionic bonding sites (Fig. 3). This result is consistent with previous reports mentioning that the electrostatic interaction between molecules increases as the number of ionic bonding sites increases. ${ }^{20}$ Therefore, 12 NNP12 with an asymmetric core and two ionic bonding sites was found to be suitable as an LC material owing to the wide temperature range capability of the LC phase.

\subsection{About the SmC phase in 12NNP12}

In general, the appearance of the SmC phase is rare in ionic LC compounds because phase separation supports the formation of the LC phase. We investigated the formation of the LC phase comprising molecules tilted from the normal of the layer in the 12NNP12 compound which has an asymmetric core. The expression of the SmC phase in non-ionic LC compounds is

Table 1 Thermodynamic properties of the compounds obtained in this study. Phase transition temperatures and enthalpies were determined by DSC thermograms

\begin{tabular}{|c|c|c|c|c|c|c|c|}
\hline & & $\begin{array}{l}T_{1} /{ }^{\circ} \mathrm{C}\left(\Delta H_{1} / \mathrm{kJ} \mathrm{mol}^{-1}\right) \text { on heating } \\
T_{1} /{ }^{\circ} \mathrm{C}\left(\Delta H_{1} / \mathrm{kJ} \mathrm{mol}^{-1}\right) \text { on cooling }\end{array}$ & & $\begin{array}{l}T_{2} /{ }^{\circ} \mathrm{C}\left(\Delta H_{2} / \mathrm{kJ} \mathrm{mol}^{-1}\right) \text { on heating } \\
T_{2} /{ }^{\circ} \mathrm{C}\left(\Delta H_{2} / \mathrm{kJ} \mathrm{mol}^{-1}\right) \text { on cooling }\end{array}$ & & $\begin{array}{l}T_{3} /{ }^{\circ} \mathrm{C}\left(\Delta H_{3} / \mathrm{kJ} \mathrm{mol}^{-1}\right) \text { on heating } \\
T_{3} /{ }^{\circ} \mathrm{C}\left(\Delta H_{3} / \mathrm{kJ} \mathrm{mol}^{-1}\right) \text { on cooling }\end{array}$ & \\
\hline 12NNP12 & Cry. & $3.8(-20.8)$ & $\mathrm{SmC}$ & $171.0(-2.21)$ & SmA & $227.6(-4.62)$ & Iso. \\
\hline 12NPP12 & Cry. 2 & $6.6(19.5)$ & Cry.1 & $58.6(31.9)$ & SmA & $136.1(8.28)$ & Iso. \\
\hline \multirow[t]{2}{*}{ 12NPN12 } & Cry. & $107.1(-61.2)$ & $\mathrm{SmB}_{\text {tetra }}$ & $194.8(-12.6)$ & Iso. & & \\
\hline & Cry. & $95.8(63.9)$ & $\mathrm{SmB}_{\text {tetra }}$ & $191.8(12.0)$ & Iso. & & \\
\hline \multirow{2}{*}{ 8NNP12 } & Cry. & $20.1(-8.31)$ & $\operatorname{SmX}$ & $113.0(-1.14)$ & Iso. & & \\
\hline & Cry. & $-10.0(9.62)$ & $\operatorname{SmX}$ & $110.1(1.06)$ & Iso. & & \\
\hline \multirow[t]{2}{*}{ 10NNP12 } & Cry. & $8.7(-10.3)$ & $\mathrm{SmC}$ & $157.4(-1.10)$ & SmA & $189.3(-3.49)$ & Iso. \\
\hline & Cry. & $-17.4(8.60)$ & $\mathrm{SmC}$ & $156.2(1.01)$ & SmA & $186.8(1.90)$ & Iso. \\
\hline \multirow[t]{2}{*}{ 14NNP12 } & Cry. & $28.3(-22.8)$ & $\mathrm{SmC}$ & $162.9(-1.12)$ & SmA & $247.6(-3.17)$ & Iso. \\
\hline & Cry. & $19.2(24.6)$ & $\mathrm{SmC}$ & $161.4(0.88)$ & SmA & $245.7(2.77)$ & Iso. \\
\hline 16NNP12 & Cry. & $44.9(-27.0)$ & $\mathrm{SmC}$ & $159.0(-1.04)$ & SmA & $260.5(-5.12)$ & Iso. \\
\hline
\end{tabular}

${ }^{a}$ Supercooling. 

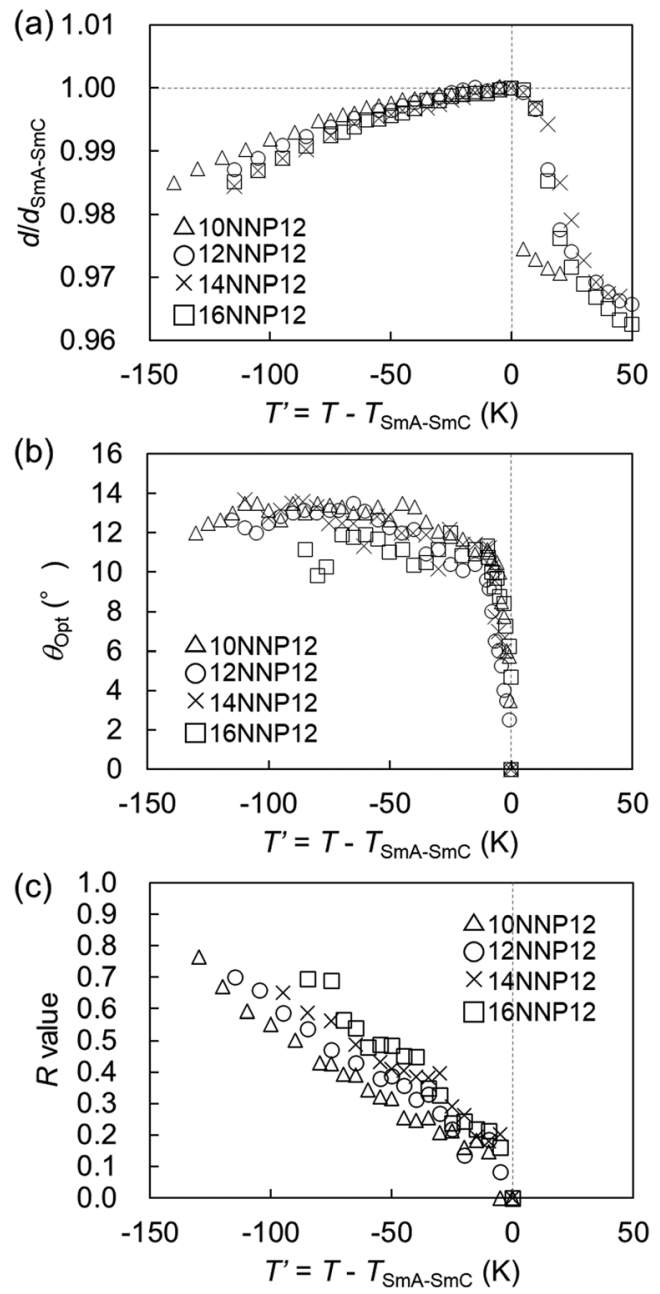

Fig. 4 (a) Layer shrinkage ( $d / d_{\text {SmA-SmC }}$ ) of $n$ NNP12 ( $\left.n=10,12,14,16\right)$ determined from layer spacing $d$ in XRD measurements vs. reduced temperature $T^{\prime}=T-T_{\text {SmA-Smc. }}$ (b) Optical tilt angles $\theta_{\text {Opt }}$ for $n$ NNP12 ( $n=10,12,14,16)$ determined by POM. (c) $R$ values calculated from $d / d_{\mathrm{SmA}-\mathrm{SmC}}$ and $\theta_{\mathrm{Opt}}$.

often explained by steric models based on the packing of alkyl chains ${ }^{21}$ and molecular models based on the dipole-dipole interactions. ${ }^{22}$ In 12NNP12, we assumed that the molecular tilt from the normal to the layer is due to the alignment of two dipole moments between cations on a rigid moiety and counter anions in the compound, as in the case of McMillan's theoretical model. Moreover, W. L. McMillan reported that the coupling of the dipoles at the ends of the core generates torque, which tilts the molecules away from the layer normal. ${ }^{22,23}$ This may explain why the SmC phase does not appear in 12NPP12 with only one dipole.

The interlayer spacing of the SmC phase is often smaller than that of the SmA phase in general LC compounds, because the molecules of the SmC phase tilt from the normal of the layer as the temperature is decreased..$^{24,25}$ The XRD measurements during the cooling process of 12NNP12 exhibited an increase in the interlayer spacing $d$ of the SmA phase before the SmA-SmC phase transition. When the temperature was

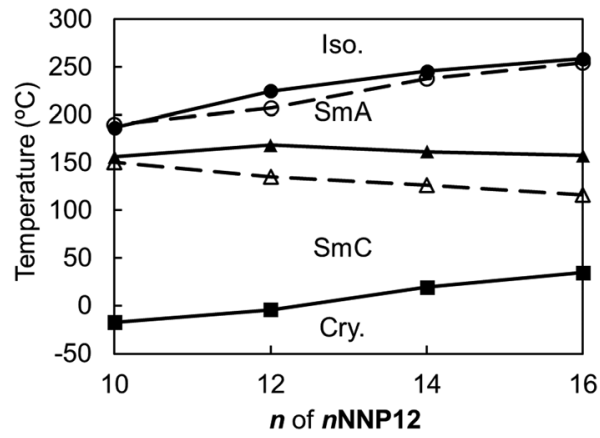

Fig. 5 Phase-transition temperatures of $n$ NNP12 $(n=10,12,14,16)$ determined by DSC (filled circles and solid lines) and POM (white circles and dashed lines).

lowered further, a layer shrinkage $\left(d / d_{\mathrm{SmA} \text {-SmC }}\right)$ of $1.3 \%$ was measured over a wide temperature range of $115 \mathrm{~K}$ in the SmC phase, as shown in Fig. 4(a). The temperature range of the SmC phase of 12NNP12 is more than $115 \mathrm{~K}$, but measurements beyond this range were limited by the equipment capabilities. 12NNP12 may be a de Vries material because of the small layer shrinkage in the SmC phase. Note that a de Vries material is an LC compound that exhibits a small interlayer shrinkage in the SmC phase. ${ }^{25-31}$ The de Vries diffusion cone model explains that the layer shrinkage in the SmC phase is smaller because the molecules are tilted away from the normal of the layer in the SmA phase. ${ }^{32,33}$ As the temperature decreased from the SmA-SmC phase transition, the layer shrinkage ratio of de Vries materials first decreased and then increased above 1, which clearly indicates the de Vries property. ${ }^{34}$ The reduction factor $R$ calculated using eqn (1) can be used to evaluate the de Vries properties. ${ }^{35,36}$

$$
R=\frac{\theta_{\mathrm{Xray}}}{\theta_{\mathrm{Opt}}}=\frac{\cos ^{-1}\left(\frac{d}{d_{\mathrm{SmA}-\mathrm{SmC}}}\right)}{\theta_{\mathrm{Opt}}}
$$

As the temperature decreased from the SmA-SmC phase transition, the tilt angle $\left(\theta_{\text {Opt }}\right)$ measured experimentally by POM increased rapidly and became constant at approximately 10-14 . The $R$-value of 12 NNP12 increased sluggishly up to 0.7 , over a temperature range of approximately $115{ }^{\circ} \mathrm{C}$. The $R$-value of 12NNP12 was 0.27 at reduced temperature $T^{\prime}=$ $-30 \mathrm{~K}$, which is as small as those of de Vries materials, but they continued to increase with decreasing temperature, which unfortunately impedes the conclusion that it is a de Vries material.

\subsection{Effect of the length of alkyl chains in $n$ NNP12 on LC properties}

Similar to the non-ionic LC compounds, the length of the alkyl chain affects the appearance of the LC phase in the ionic viologens. Therefore, while the length of the alkyl chain attached to the aromatic ring of the NNP core was fixed, the length of the alkyl chain attached to the pyridine ring of the NNP core ( $n$ of $n \mathbf{N N P 1 2}$ ) was changed. The $n \mathbf{N N P 1 2}(n=10,14$, and 16) 
compounds as well as 12NNP12 exhibited SmA and SmC phases. The $R$-values of $n$ NNP12 ( $n=10,14$, and 16) were almost equal to those of 12NNP12 and did not depend on $n$. As $n$ increased from 10 to 16 , both $T_{\text {LC-Cry }}$ and $T_{\text {Iso-LC }}$ increased sluggishly over $50{ }^{\circ} \mathrm{C}$, as shown in Fig. 5. This means that the alkyl chains contribute to the thermal stabilisation of both the crystalline and LC phases. In 8NNP12, a high-order LC phase appeared (Fig. S14-S16, ESI $\dagger$ ). In the case of $\mathbf{4 N N P 1 2}$, the LC phase did not appear, and DSC measurements confirmed the supercooling phenomenon (Fig. S14-S16, ESI $\dagger$ ). It was found that the shorter the $n$ in $n$ NNP12 is, the less LC phase was observed. These results indicate that the length of the alkyl chain influences the formation of the LC phase, even in viologens with an asymmetric core. However, asymmetrisation by alkyl chains was found to be less effective than that by rigid moieties.

\section{Conclusions}

We synthesised viologen 12NNP12, which has an extended core asymmetrised by the introduction of an aromatic ring on one side of the bipyridine, with the aim of forming a low-order LC phase around ambient temperature (approximately $20{ }^{\circ} \mathrm{C}$ ). 12NNP12 exhibited low-order LC phases, SmA and SmC, the latter of which appeared in a wide temperature range $\left(172.6{ }^{\circ} \mathrm{C}\right)$ above $-4.2{ }^{\circ} \mathrm{C}$. This is the first report of the formation of the SmC phase in a simple viologen without the functional groups known to give rise to the SmC phase. In addition, 12NNP12 showed a small layer shrinkage of the SmC phase, which is similar to the de Vries-type material, although it cannot be determined absolutely. Moreover, the effects of a symmetric or an asymmetric core on the LC properties of viologen derivatives have been reported from the viewpoint of molecular structures. 12NPN12 with a symmetric core showed the $\mathrm{SmB}_{\text {tetra }}$ phase, while $12 \mathrm{NPP12}$ with an asymmetric core exhibited the SmA phase. It was suggested that compounds with a symmetric ionic core tend to form high-order smectic phases due to electrostatic interactions in the direction of the short axis of the molecule, while the intermolecular interactions were weakened by varying the position of the ionic bonding sites on the core to make them asymmetric, resulting in low-order LC phases. Even in the viologen $n \mathbf{N N P 1 2}$, which has an asymmetric core, the LC phase did not appear when the alkyl chain length was shortened. However, the asymmetry of the ionic rigid moiety affects the LC properties more than the asymmetry of the alkyl chain.

As shown above, development of guidelines of the molecular design for the achievement of a low-order LC phase at a wide temperature range is the subject of our current research. If the photo-induced reduction of a viologen exhibiting the low-order LC phase could be triggered to change the alignment of the mesogens, it could be used as a refractive-index modulation holographic material.

\section{Author contributions}

Y. Naka conceived the research, supervised, and coordinated the project. S. Arai, Y. Ohgi, and M. Takahashi carried out the synthesis of LC compounds and LC characterisation. K. V. Le and T. Sasaki provided beneficial advice regarding the research.

\section{Conflicts of interest}

There are no conflicts to declare.

\section{Acknowledgements}

This work was supported by JSPS KAKENHI (Grant Number 17K14532).

\section{Notes and references}

1 S. W. Boettcher, J. M. Spurgeon, M. C. Putnam, E. L. Warren, D. B. Turner-Evans, M. D. Kelzenberg, J. R. Maiolo, H. A. Atwater and N. S. Lewis, Science, 2010, 327, 185-187.

2 L. Striepe and T. Baumgartner, Chem. - Eur. J., 2017, 23, 16924-16940.

3 Y. Alesanco, A. Vinuales, G. Cabanero, J. Rodriguez and R. Tena-Zaera, ACS Appl. Mater. Interfaces, 2016, 8, 29619-29627.

4 J. Ding, C. Zheng, L. Wang, C. Lu, B. Zhang, Y. Chen, M. Li, G. Zhai and X. Zhuang, J. Mater. Chem. A, 2019, 7, 23337-23360.

5 T. T. Do, H. S. Hong, Y. E. Ha, J. Park, Y.-C. Kang and J. H. Kim, ACS Appl. Mater. Interfaces, 2015, 7, 3335-3341.

6 P. M. S. Monk, The viologens: physicochemical properties, synthesis and applications of the salts of 4,4'-bipyridine, Wiley, 1998.

7 P. K. Bhowmik, O. Noori, S. L. Chen, H. Han, M. R. Fisch, C. M. Robb, A. Variyam and A. Martinez-Felipe, J. Mol. Liq., 2021, 328, 115370.

8 V. Causin and G. Saielli, J. Mater. Chem., 2009, 19, 9153-9162.

9 I. Pibiri, A. Beneduci, M. Carraro, V. Causin, G. Casella, G. A. Corrente, G. Chidichimo, A. Pace, A. Riccobono and G. Saielli, J. Mater. Chem. C, 2019, 7, 7974-7983.

10 Y. Haramoto, M. Yin, Y. Matukawa, S. Ujiie and M. Nanasawa, Liq. Cryst., 1995, 19, 319-320.

11 R.-T. Wang, G.-H. Lee and C. K. Lai, J. Mater. Chem. C, 2018, 6, 9430-9444.

12 L. Veltri, G. Cavallo, A. Beneduci, P. Metrangolo, G. A. Corrente, M. Ursini, R. Romeo, G. Terraneo and B. Gabriele, New J. Chem., 2019, 43, 18285-18293.

13 Y. Zheng, J. Wang, X. Tang, L. Zhang and F. Meng, J. Mol. Liq., 2020, 301, 112369.

14 M. F. Pepitone, G. G. Jernigan, J. S. Melinger and O. K. Kim, Org. Lett., 2007, 9, 801-804.

15 S. Asaftei and E. De Clercq, J. Med. Chem., 2010, 53, 3480-3488.

16 N. Zeghbib, P. Thelliere, M. Rivard and T. Martens, J. Org. Chem., 2016, 81, 3256-3262.

17 M. Eda, M. J. Kurth and M. H. Nantz, J. Org. Chem., 2000, 65, 5131-5135.

18 M. Bonchio, M. Carraro, G. Casella, V. Causin, F. Rastrelli and G. Saielli, Phys. Chem. Chem. Phys., 2012, 14, 2710-2717. 
19 E. Alami, H. Levy, R. Zana, P. Weber and A. Skoulios, Liq. Cryst., 1993, 13, 201-212.

20 S. Ujiie and K. Iimura, Chem. Lett., 1994, 17-20.

21 A. Wulf, Phys. Rev. A: At., Mol., Opt. Phys., 1975, 11, 365-375.

22 W. L. McMillan, Phys. Rev. A: At., Mol., Opt. Phys., 1973, 8, 1921-1929.

23 J. W. Goodby, P. J. Collings, T. Kato, C. Tschierske, H. F. Gleeson and P. Raynes, Smectic and Columnar Liquid Crystals, Wiley-VCH Verlag GmbH \& Co. KGaA, 2nd edn, 2014, vol. 4, pp. 10-13.

24 J. W. Goodby, P. J. Collings, T. Kato, C. Tschierske, H. F. Gleeson and P. Raynes, Fundamentals of Liquid Crystals, Wiley-VCH Verlag GmbH \& Co. KGaA, 2nd edn, 2014, vol. 1, pp. 323-324.

25 J. P. F. Lagerwall and F. Giesselmann, ChemPhysChem, 2006, 7, 20-45.

26 Q. Song, D. Nonnenmacher, F. Giesselmann and R. P. Lemieux, Chem. Commun., 2011, 47, 4781-4783.

27 N. Kapernaum, C. Muller, S. Moors, M. C. Schlick, F. Giesselmann, E. Wuckert and S. Laschat, ChemPhysChem, 2016, 17, 4116-4123.
28 K. Bader, C. Mueller, Y. Molard, A. Baro, P. Ehni, J. Knelles and S. Laschat, RSC Adv., 2020, 10, 23999-24016.

29 K. M. Mulligan, A. Bogner, Q. Song, C. P. J. Schubert, F. Giesselmann and R. P. Lemieux, J. Mater. Chem. C, 2014, 2, 8270-8276.

30 N. Ishida, Y. Takanishi, J. Yamamoto and A. Yoshizawa, Appl. Phys. Express, 2011, 4, 021701.

31 S. P. Sreenilayam, D. Rodriguez-Lojo, V. P. Panov, V. Swaminathan, J. K. Vij, Y. P. Panarin, E. Gorecka, A. Panov and P. J. Stevenson, Phys. Rev. E, 2017, 96, 042701.

32 A. De Vries, J. Chem. Phys., 1979, 71, 25-31.

33 A. Wulf, Phys. Rev. A: At., Mol., Opt. Phys., 1978, 17, 2077-2082.

34 C. P. J. Schubert, C. Muller, A. Bogner, F. Giesselmann and R. P. Lemieux, Soft Matter, 2017, 13, 3307-3313.

35 Y. Takanishi, Y. Ouchi, H. Takezoe, A. Fukuda, A. Mochizuki and M. Nakatsuka, Jpn. J. Appl. Phys., Part 2, 1990, 29, L984-L986.

36 M. D. Radcliffe, M. L. Brostrom, K. A. Epstein, A. G. Rappaport, B. N. Thomas, R. Shao and N. A. Clark, Liq. Cryst., 1999, 26, 789-794. 